\title{
Sexual behaviour in Zulu men and women with genital ulcer disease
}

\author{
N O’Farrell, A A Hoosen, K D Coetzee, J van den Ende
}

\begin{abstract}
Objective-To investigate patterns of sexual behaviour in men and women with genital ulcer disease (GUD) and their relevance to HIV-1 transmission.

Methods-A sexual behaviour questionnaire was administered by the same interviewer to all participants who were also entered into a study of the microbial aetiology of GUD.
\end{abstract}

Setting-City Health Sexually Transmitted Diseases Clinic, King Edward VIII Hospital, Durban, South Africa.

Participants-100 Zulu men and 100 Zulu women.

Results-36 (\%) of men and $36(\%)$ of women had continued with sexual intercourse despite GUD. Patients with donovanosis and secondary syphilis were more likely than those with other causes of GUD to have intercourse despite ulcers. During swab collection bleeding was observed from ulcers in 59 women and 26 men. Prostitutes were not identified and were rarely named as source contacts. Men had more sexual partners (190) than women (122) during the previous three months. Condom use was minimal. Men who migrated between urban and rural areas appeared to have the most sexual partners. Urban women had more partners than women from rural areas.

Conclusions-Men and women with GUD are practising riskful sexual behaviour and could benefit from behaviour modification programmes. In this community men who travel between urban and rural areas and who present late with GUD that bleeds easily are probably the most important high-frequency HIV transmitter core group. A significant potential risk of blood to blood contact during sexual intercourse exists in patients with GUD.

City Health STD

Clinic, King Edward VIII Hospital, Durban N O'Farrell

Department of Medical Microbiology, Faculty of Medicine, University of Natal,

Durban, South Africa A A Hoosen

K D Coetzee

J van den Ende

Address correspondence to Dr Nigel O'Farrell, Lydia Department, St Thomas'

Hospital, London SE1 7EH.

Accepted for publication

23 March 1992

\section{Introduction}

The spread of HIV infection is currently greatest in sub-Saharan Africa where most cases are acquired through heterosexual intercourse. Factors contributing to the epidemic include a high prevalence of sexually transmitted diseases (STD), multiple sexual partners, prostitution, poverty, lack of education and high risk sexual practices. ${ }^{12}$ The relative importance of these factors varies between communities and may explain the heterogeneous pattern of HIV infection reported between countries with common borders. ${ }^{1}$

One STD syndrome, genital ulcer disease
(GUD), is a major public health problem in East and Southern Africa and a well established risk factor in Nairobi for acquiring and transmitting $\mathrm{HIV}^{34}$ In South Africa where HIV was only relatively recently identified in 1988 amongst heterosexuals attending an STD clinic, $^{5}$ GUD is also associated with an increased risk of HIV infection.

It would seem plausible that patients with GUD refrain from sexual intercourse until healing is achieved. However, a pilot study amongst local men with donovanosis suggested that GUD acted only partially as a deterrent to sexual intercourse. ${ }^{7}$ The degree of pain associated with GUD varies with the cause and is greater with chancroid and genital herpes than with primary and secondary syphilis or donovanosis. If ulcers remain untreated either through patients' non-recognition of GUD as an STD, unavailability of medical care or incorrect diagnosis, the likelihood of sexual intercourse in the presence of GUD, particularly if painless, must increase.

The implementation of beneficial behavioural interventions in groups identified at high risk both of acquiring and transmitting HIV infection is an important aim of any AIDS control programme. Men and women with GUD are one such risk group but little is known about their sexual behaviour. We therefore investigated sexual behaviour in patients with GUD in Durban, Natal, where the HIV seroprevalence rate is now the highest amongst the black population in South Africa. ${ }^{8}$

\section{Patients and methods}

The participants were 100 Zulu men and 100 Zulu women with GUD attending the City Health STD Clinic, King Edward VIII Hospital, Durban, who were entered into a study of the microbial aetiology of genital ulcers. All ulcers were evaluated by standard microbiological techniques. The methods employed are described elsewhere. ${ }^{910}$ All subjects underwent an interview with the same doctor. A nursing sister acted as interpreter for the women and a male health assistant similarly for the men. A detailed history was obtained and a questionnaire completed relating to previous and current sexual practices and contraceptive methods.

\section{Results}

All patients agreed to participate and completed the questionnaire. Details of demographic, clinical and epidemiological features, pathogens isolated from ulcers, other 
Table 1 Sexual intercourse in the presence of various causes of GUD in 100 men (M) and 100 women (W)

\begin{tabular}{|c|c|c|c|c|}
\hline \multirow[b]{2}{*}{ Feature } & \multirow[b]{2}{*}{$\boldsymbol{M}$} & \multirow[b]{2}{*}{$W$} & \multicolumn{2}{|c|}{$\begin{array}{l}\text { Sexual intercourse despite } \\
\text { GUD }\end{array}$} \\
\hline & & & $\boldsymbol{M}$ & $W$ \\
\hline $\begin{array}{l}\text { Primary syphilis } \\
\text { Secondary syphilis } \\
\text { Primary + secondary syphilis } \\
\text { Chancroid } \\
\text { Genital herpes } \\
\text { Donovanosis } \\
\text { Lymphogranuloma } \\
\text { venereum }\end{array}$ & $\begin{array}{l}\mathrm{N}=29(\%) \\
- \\
\bar{N}=12(\%) \\
\mathrm{N}=9(\%) \\
\mathrm{N}=9(\%) \\
\mathrm{N}=3(\%)\end{array}$ & $\begin{array}{l}\mathbf{N}=11(\%) \\
\mathbf{N}=15(\%) \\
\mathbf{N}=2(\%) \\
\mathbf{N}=12(\%) \\
\mathbf{N}=12(\%) \\
\mathbf{N}=10(\%) \\
\mathbf{N}=5(\%)\end{array}$ & $\begin{array}{l}10(34) \\
= \\
3(25) \\
2(22) \\
4(44) \\
1(33)\end{array}$ & $\begin{array}{l}4(36) \\
7(47) \\
2(100) \\
3(25) \\
3(25) \\
8(80) \\
2(40)\end{array}$ \\
\hline $\begin{array}{l}\text { Mixed infections } \\
\text { No cause identified } \\
\text { Scabies }\end{array}$ & $\begin{array}{l}\mathrm{N}=14(\%) \\
\mathrm{N}=24(\%)\end{array}$ & $\begin{array}{l}\mathbf{N}=13(\%) \\
\mathbf{N}=18(\%) \\
\mathbf{N}=2(\%)\end{array}$ & $\begin{array}{r}6(43) \\
10(42) \\
-\end{array}$ & $\begin{array}{l}3(23) \\
3(17) \\
1(50)\end{array}$ \\
\hline
\end{tabular}

Table 2 Sexual behaviour and bleeding observed from GUD in 100 Zulu men and 100 Zulu women

\begin{tabular}{lcc}
\hline & Men No (\%) & Women No (\%) \\
\hline Sexual Intercourse (SD) despite GUD & 36 & 36 \\
Bleeding from ulcer during swab collection & 26 & 59 \\
SI with noticeable bleeding despite GUD & 6 & 7 \\
SI during menstruation at least once & 18 & 4 \\
Anal intercourse with opposite sex at least once & 4 & 0 \\
Condom use: & 89 & 99 \\
Never & 7 & 1 \\
Within last 6 months & - & 3 \\
Nos of sexual partners in last 3 months: & 40 & 75 \\
0 & 42 & 19 \\
1 & 11 & 3 \\
2 & 5 & 7 \\
3 & 2 & 122 \\
4 & 190 & 12 \\
$>5$ & 35 & 94 \\
Total No & 21 & 6 \\
Lifetime sexual partners: & 35 & - \\
$1-5$ & 5 & - \\
$6-10$ & 4 & - \\
$11-25$ & - & 16.4 \\
$26-75$ & - & \\
$76-250$ & 250 &
\end{tabular}

conditions and causes of GUD are reported elsewhere. ${ }^{910}$ Ninety-eight men were uncircumcised.

Thirty-six of the men and 36 of the women admitted sexual intercourse following the onset of ulceration. The proportion of those who had sexual intercourse in the presence of GUD varied according to its cause (table 1) Six men and seven women had noticed bleeding from ulcers after sexual intercourse (table 2). When swabs were applied to ulcers to obtain microbiological specimens, bleeding was observed in 59 women and 26 men.

None of the men admitted homosexual contacts. During the previous three months, men (190) had more sexual partners than women (122), with most of the men $(82 \%)$ having either one or two contacts (table 2). The majority (91\%) of men had less than 25 lifetime sexual partners. Five men admitted contact with a prostitute as the likely source of

Table 3 Geographic locations of sexual partners of 100 men (M) and 100 women (W) with GUD

\begin{tabular}{|c|c|c|c|c|c|c|}
\hline & \multicolumn{2}{|c|}{ Urban Only } & \multicolumn{2}{|c|}{ Urban + Rural } & \multicolumn{2}{|c|}{ Rural Only } \\
\hline & $\boldsymbol{M}$ & $W$ & $\boldsymbol{M}$ & $W$ & $M$ & $\mathbb{W}$ \\
\hline $\begin{array}{l}\text { No of sexual } \\
\text { partmers in } \\
\text { previous } 3 \text { months } \\
\text { Total: } \\
\text { Mean: }\end{array}$ & $\begin{array}{l}N=57 \\
110 \\
1 \cdot 9\end{array}$ & $\begin{array}{l}N=63 \\
82 \\
1 \cdot 3\end{array}$ & $\begin{array}{l}N=23 \\
49 \\
2 \cdot 1\end{array}$ & $\begin{array}{l}N=6 \\
10 \\
1 \cdot 7\end{array}$ & $\begin{array}{l}N=20 \\
31 \\
1 \cdot 6\end{array}$ & $\begin{array}{l}\mathrm{N}=31 \\
30 \\
1 \cdot 0\end{array}$ \\
\hline
\end{tabular}

GUD. Eighteen men had had sexual contact during their partners' menses; four admitted anal intercourse at least once but none regularly.

The majority (94\%) of women had either one or two sexual partners in the previous three months. Ninety-four had less than five lifetime sexual partners and six had from six to 10. The average age of first intercourse in women was 16.4 (range 12-26) years. Four women admitted intercourse very occasionally during menses. None of the women admitted accepting money for sex and all denied anal intercourse.

Condoms had been used by seven men during the previous six months and never by 89 (table 2). Only one of the women had ever used condoms. Depot injection (18\%) was the most favoured method of contraception. Forty-two women had never used any contraception and 72 currently used no method.

Men with sexual partners from both urban and rural areas (table 3) appeared to have the highest mean number of partners. Women with partners from urban areas had more contacts than those from rural areas alone.

\section{Discussion}

This study has shown that Zulu men and women frequently continue with sexual intercourse despite the presence of GUD. When swabs were applied to ulcers to obtain material for microbiological analysis, bleeding was observed in $59 \%$ of women ${ }^{9}$ and $26 \%$ of men ${ }^{10}$ suggesting that in this population exchange of blood during sexual intercourse is likely to be common. Since HIV-1 has been isolated from genital ulcers and the risk of HIV transmission may be increased by sexual intercourse with genital trauma and during menses, ${ }^{11}$ the sexual behaviour of our patients must be regarded as high risk both for acquisition and transmission of the virus.

Men and women with donovanosis and women with secondary syphilis were more likely than patients with other causes of GUD to present late ${ }^{10}$ and to continue with intercourse despite GUD. Donovanosis ulcers were large and bled easily ${ }^{10}$ thereby presenting a significant theoretical biological risk of HIV transmission.

Almost all of the men in this study were uncircumcised and thus at increased risk of GUD. ${ }^{12}$ The intact foreskin is an independent risk factor for acquiring $\mathrm{HIV}^{3}$ and a consistent finding in African communities worst affected by HIV-1. ${ }^{1314}$ It may be that men with intact foreskin and subpreputial ulcers delay in seeking medical attention and take less notice of lesions than circumcised men in whom ulcers are readily apparent.

Women had few sexual partners in keeping with the low numbers of sexual partners reported by HIV-1 seropositive women in Durban. ${ }^{15}$ In assessing the risk of HIV acquisition in women, the number of sexual partners of male contacts may be a more important determinant than the numbers of partners of women alone in this population. Men who had 
recent partners from both urban and rural areas had more sexual contacts than those remaining in one location although it should be said our sample size was limited. Thus as in Rwanda ${ }^{16}$ travellers to cities are the most likely source vectors of HIV transmission to rural communities.

In this study prostitutes were not identified amongst clinic attenders and were rarely named as source contacts. This pattern differs from Nairobi, where prostitutes are a key core group of STD transmitters, ${ }^{17}$ but is similar to Uganda where cultural factors provide men with higher than average opportunities to find sexual partners and not seek prostitutes. ${ }^{18}$ Although an important group to be targeted, prostitutes may occupy a lesser role in the spread of HIV-1 in Durban than in other parts of Africa.

Despite a recent promotional campaign, condoms were used rarely and are still regarded primarily as a method of birth control. At the time of the study availability of condoms was sporadic and patients were limited to one only. In many African countries tradition and peer group pressure encourages large families, particularly in areas with high infant mortality rates. Locally condoms have, until recently, only been available from Family Planning clinics and there is suspicion that their promotion is directed solely towards limiting population growth.

Male homosexuals were not identified in this study and are rarely seen at this clinic, although ex-prisoners occasionally admit homosexual contact whilst in prison. Anal intercourse was uncommon. Interpreters were unhappy about obtaining this information which they regarded as irrelevant. By selecting interviewers of the same ethnic origins and spoken language of the sample, the threat respondents may feel when interviewed by persons of a different culture was minimized. ${ }^{19}$ Questions were designed to elicit straightforward responses in most cases, thus obviating the need for lengthy explanations that could lead to inconsistent interpretation.

It would appear that patients with GUD, particularly uncircumcised men with GUD, are an important core group of high risk HIV transmitters in this population and are practising unsafe sex. Such individuals, who may readily transmit HIV and have a rapid turnover of sexual partners, are difficult to identify and widely scattered in the community. These patients may attend STD clinics but in surroundings that are over-crowded, short-staffed and without privacy, opportunities for basic health education have been limited so far. All patients with GUD should ideally be counselled about the infectivity of HIV and GUD. The recent recognition locally of herpes simplex virus (HSV) as a significant cause of GUD in men ${ }^{10}$ and women 9 reinforces the role of education and explanation in the management of GUD.

Given the current lack of resources, clinic priorities may need to be reassessed at least in the short term. In this clinic most of the current workload is directed towards the diag- nosis and treatment of some 10,000 cases of gonorrhoea per annum in men. Neisseria gonorrhoeae has been isolated from $96 \%$ of local men with urethral discharge ${ }^{20}$ and it would seem logical to treat such cases empirically for gonorrhoea and free clinic personnel to provide health education for patients with GUD who are at greater risk of HIV infection than men with urethritis. ${ }^{6}$ However, the role of $N$ gonorrhoeae and also Chlamydia trachomatis and vaginal pathogens in the spread of HIV should not be underestimated. Women with nonulcerative STD may be at increased risk of $\mathrm{HIV}-\mathrm{1}^{21}$ and a full diagnostic service for these infections should ideally be provided for all women attending STD clinics.

Durban now has the highest number of cumulative AIDS cases acquired through heterosexual intercourse amongst the black community in South Africa ${ }^{8}$ despite its geographical location in the south, away from countries with higher HIV seroprevalence rates. Current projections suggest that the level of HIV infection in South Africa is now higher than in Uganda, considered to be the worst-hit country in Africa. ${ }^{22}$ The sexual practices described in this study may partly explain these estimates and indicate that behaviour modification in high risk core groups attending STD clinics should be targeted in the public health control of GUD and HIV.

We thank the staff at the City Health STD Clinic including all doctors, sisters and health assistants for their co-operation.

1 Piot $\mathrm{P}$, Laga $\mathrm{M}$, Ryder R, et al. The global epidemiology of HIV infection: continuity, heterogeneity, and change. $\%$ AIDS 1990;3:403-12.

2 Prual A, Chacko S, Koch-Weser D. Sexual behaviour, AIDS and poverty in sub-Saharan Africa. Int $\mathcal{J}$ STD AIDS 1991;2:1-9.

3 Cameron DW, Simonsen JN, D'Costa LJ, et al. Female to male transmission of human immunodeficiency virus type 1: risk factors for seroconversion in men. Lancet 1989; ii:403-7.

4 Plummer FA, Cameron DW, Simonsen JN, et al. Cofactors in male-female transmission of HIV. $\mathcal{F}$ Infect Dis 1991; 163:233-9.

5 O'Farrell N, Windsor I. Prevalence of HIV-antibodies in recurrent attenders at a sexually transmitted diseases clinic. $S$ Afr Med $\Im$ 1988;74:104-5.

6 O'Farrell N, Windsor I, Becker P. HIV-1 infection among heterosexual attenders at a sexually transmitted diseases heterosexual attenders at a sexually transmitted
clinic in Durban. $S$ Afr Med $\mathcal{f} 1991 ; 80: 17-20$.

7 O'Farrell N. AIDS, Sex, Genital Ulceration. Lancet 1988;i:355.

8 Department of National Health and Population Development. AIDS in South Africa: Status on World AIDS Day 1991. Epidemiological Comments 1991;18:229-47.

9 O'Farrell N, Hoosen AA, Coetzee K, van den Ende J. Genital ulcer disease in women in Durban, South Africa. Genitourin Med 1991;67:322-6.

10 O'Farrell N, Hoosen AA, Coetzee K, van den Ende J. Genital ulcer disease in men in Durban, South Africa. Genitourin Med 1991;67:327-30.

11 Hellman NS, Desmond-Hellman S, Nsubuga PS, Baingana-Baingi, Mbidde EK, Tager IB. Genital trauma gana-Baingi, Mbidde EK, Tager IB. Genital trauma
during sex is a high risk factor for HIV infection in during sex is a high risk factor for HIV infection in
Uganda. VII International Conference on AIDS, June Uganda. VII International Conference on

12 Hart G. Factors influencing venereal infection in a war
16-21 1991, Florence (Abstract $M C 3079$ ). environment. Br f Venereal Dis 1974;50:68-72.

13 Bongaarts J, Reining P, Way P, Conant F. The relationship between male circumcision and HIV infection in African populations. AIDS 1989;3:373-7.

14 Moses S, Bradley JE, Nagelkerke NJ, Ronald AR, NdinyaAchola JO, Plummer FA. Geographical patterns of male circumcision practices in Africa: association with HIV seroprevalence. Int $\Im$ Epidemiol 1990;19:693-7.

15 O'Farrell N, Windsor I. Sexual behaviour in HiV-1 seropositive men and women in Durban, South Africa. $f$ AIDS 1991;4:1258-9.

16 Van de Perre P, Le Polain B, Carael M, Nzaramba D, Zissis $G$, Butzler JP. HIV antibodies in a remote rural area in Rwanda, Central Africa: an analysis of potential risk
factors for HIV seropositivity. AIDS 1987;1:213-5. 
17 Moses S, Plummer FA, Ngugi EN, Nagelkerke NJ, Anzala AO, Ndinya-Achola JO. Controlling HIV in Africa: effectiveness and cost of an intervention in a high frequency STD transmitter core group. AIDS 1991 5:407-11.

18 Larsen A. Social context of human immunodeficiency virus transmission in Africa: Historical and cultural bases of in Africa. Historical and cultural bases of 1989;11:716-31.

19 Wyatt GE. Examining ethnicity versus race in AIDS related sex research. Soc Sci Med 1991;33:37-45.
20 Hoosen AA, van den Ende J, Kharsany AB. The aetiology of acute urethritis in black males in Durban, South Africa and penicillin susceptibility of Neisseria gonorrhoeae isolates. Southern African fournal of Epidemiology \& Infection 1987;2:4-6.

21 Laga M, Nzila N, Manoka AT. Non-ulcerative sexually transmitted disease (STD) as risk factors for HIV infection. Sixth International Conference on AIDS, June 1990, San Francisco. (Abstract TH.C. 97). 22 Armstrong S. South Africa wakes up to the threat of AIDS New Scientist 1991;129:19. 